Mathematics and Computer Science Division Mathematics and Computer Science Division Mathematics and Computer Science Division

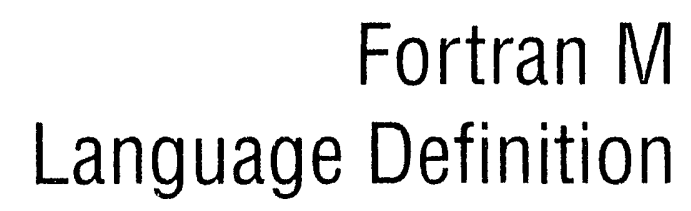

by I. T. Foster and K. M. Chandy

Argonne National Laboratory, Argonne, Illinois 60439 operated by The University of Chicago for the United States Department of Energy under Contract W-31-109-Eng-38 
Argonne National Laboratory, with facilities in the states of Illinois and Idaho, is owned by the United States government, and operated by The University of Chicago under the provisions of a contract with the Department of Energy.

\section{DISCLAIMER}

This report was prepared as an account of work sponsored by an agency of the United States Government. Neither the United States Government nor any agency there of, nor any of their employees, makes any warranty, express or implied, or assumes any legal liability or responsibility for the accuracy. completeness, or usefulness of any information. apparatus, product, or process disclosed, or represents that its use would not infringe privattely owned rights. Reference herein to any specific commerciall product, process, or service by trade name, trademark, manufiaturer, or otherwise. doess not necessarily constitute or imply its endorsement. recommendation, or favoring by the United States Government or any agency thereol. The views and opinions of authors expressed herein do not necessarily state or reflect those of the United States Government or any angency thereof.

Reproduced from the best avialable copy.

Available to DOE and DOE contractors lirom the

Office of Scientific and Technical Information

P.O. BOX 62

()ak Ridge, TN 378.31

Prices alvailable from $(615) .576-8+(0) 1$

Available to the public from the

Nalional Technical Information Service

U.S. Department of Commerce

5285 Port Royal Roal

Springlïeld, VA 22161 
Distribution Category:

Mathematics and

Computer Science (UC-405)

\section{ARGONNE NATIONAL LABORATORY \\ 9700 South Cass Avenue}

Argonne, IL 60439

ANL-93/28

\section{Fortran M Language Definition}

by

Ian T. Foster and K. Mani Chandy*

Mathematics and Computer Science Division

August 1993

This research was supported in part by the Office of Scientific Computing, U.S. Department of Energy, under Contract W-31-109-Eng-38, and by the National Science Foundation's Center for Research in Parallel Computation, under Contract CCR-8809615.

"Address: Department of Computer Science, California Institute of Technology, Pasadena, CA 91125

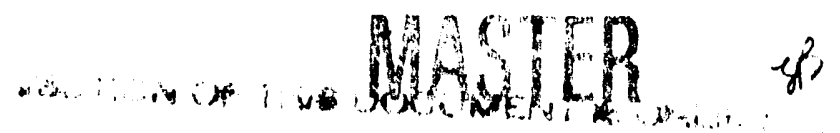




\section{Contents}

$\begin{array}{ll}\text { Abstract } & 1\end{array}$

1 Introduction $\quad 1$

2 Syntax 1

2.1 Process, Process Block, Process Do-loop . . . . . . . . . . . . . 1

2.2 New Declarations ........................ . . . . . . . . . . . . . . . . . . .

2.3 New Executable Statements . . . . . . . . . . . . . . . . 2

2.4 Mapping . . . . . . . . . . . . . . . . . . . 4

2.5 Restrictions ......................... 4

3 Concurrency 4

4 Channels 4

5 Nondeterminism $\quad$ 5

6 Mapping $\quad 6$

$\begin{array}{lc}\text { References } & 6\end{array}$ 


\title{
Fortran M Language Definition
}

\author{
Ian T. Foster K. Mani Chandy
}

\begin{abstract}
This document defines the Fortran $M$ extensions to Fortran 77. It updates an earlier definition, dated June 1992, in several minor respects.
\end{abstract}

\section{Introduction}

The reader is referred to other reports for additional information on the Fortran $M$ language [2], its theoretical foundations [1], and a Fortran M compiler developed at Argonne National Laboratory [3].

\section{Syntax}

Backus-Naur form (BNF) is used to present new syntax, with nonterminal symbols in slanted font, terminal symbols in TYPEWRITER font, and symbols defined in Appendix F of the Fortran 77 standard [4] underlined. The syntax [symbol] is used to represent, zero or more comma-separated occurrences of symbol; [symbol] ${ }^{(1)}$ represents one or more occurrences.

\subsection{Process, Process Block, Process Do-loop}

A process has the same syntax as a subroutine, except that the keyword PROCESS is substituted for SUBROUTINE, INTENT declarations can be provided for dummy arguments, and a process cannot take an assumed size array as a dummy argument.

A process call can occur anywhere that a subroutine call can occur. It has the same syntax as a subroutine call, except that the keyword PROCESSCALL is substituted for CALL. In addition, process calls can occur in process blocks and process do-loops, and recursive process calls are permitted. A process block is a set of statements preceded by a PROCESSES statement and followed by a ENDPROCESSES statement. A block includes zero or one subroutine calls, zero or more process calls, and zero or more process do-loops. A process do-loop has the same syntax as a do-loop, except that the PROCESSDO keyword is used in place of $D O$, and the body of the do-loop can contain only a process do-loop or a process call.

A port variable or port array element can be passed as an argument to only a single process in a process block or process do-loop, and then cannot be accessed in a subroutine called in that block. 


\subsection{New Declarations}

Five new declaration statements are defined: INPORT, OUTPORT, INTENT, PROCESSORS, and PROCESS COMMON.

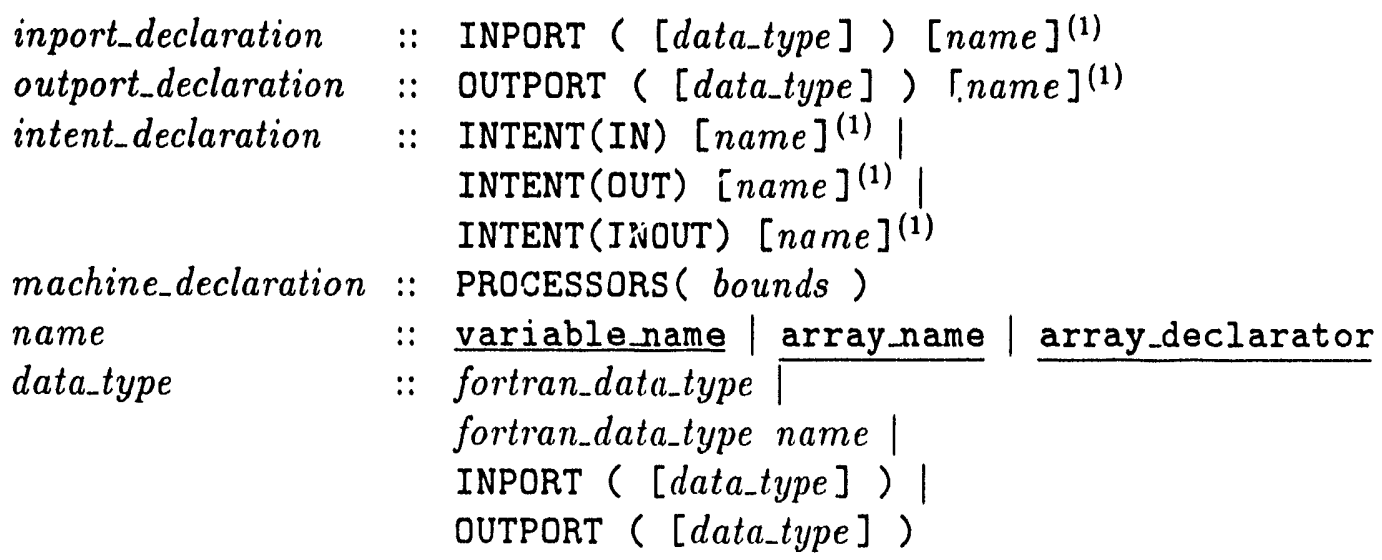

In the PROCESSORS statement, bounds has the same syntax as the arguments to an array_declarator. The product of the dimensions must be nonzero. Any program, process, subroutine, or function including a LOCATION or SUBMACHINE annotation must include a PROCESSORS declaration.

The symbol fortran_data_type denotes the six standard Fortran data types. The dimensions in an array_declarator in a port declaration can include variable declared in the port declaration, parameters, and arguments to the process or subroutine in which the declaration occurs. The symbol "*" cannot be used to specify an assumed size. Variables declared within a port declaration have scope local to that declaration.

A PROCESS COMMON statement has the same syntax as a COMMON statement.

\subsection{New Executable Statements}

There are seven new executable statements: CHANNEL, MERGER, MOVEPORT, SEND, RECEIVE, ENDCHANNEL, and PROBE. Each of these takes as arguments a list of control specifiers, termed a control information list. The SEND and RECEIVE statements also take other arguments. A control information list can include at most one of each specifier, except those that name ports. The number of allowable port specifiers varies from one statement to another. The first three of these statements are as follows.

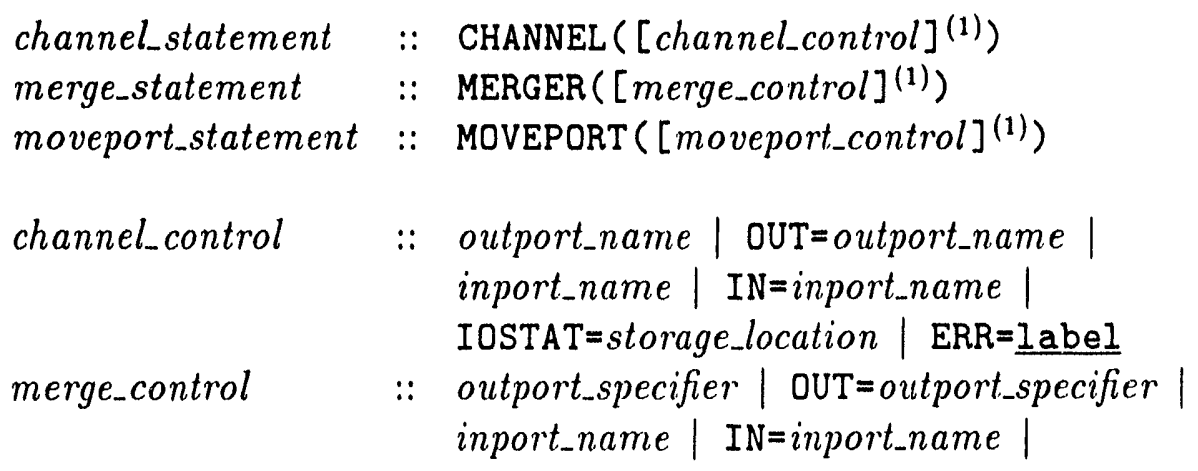




$\begin{array}{ll}\text { moveport_control } & : \text { IOSTAT=storage_location | ERR=1_abel } \\ & \begin{array}{l}\text { port_name | FROM=port_name | } \\ \text { port_name | TO=port_name | } \\ \text { IOSTAT=storage_location | ERR=I_abel }\end{array} \\ \text { outport_specifier } & :: \text { outport_name | data_implied_do_Iist } \\ \text { outport_name } & :: \text { port_name } \\ \text { inport_name } & :: \text { port_name } \\ \text { port_name } & :: \text { variable_name | array_element_name }\end{array}$

A CHANNEL statement must include two port specifiers, and these must name an outport and an in-port of the same type. If the strings OUT $=$ and $I N=$ are omitted, these specifiers must occur as the first and second arguments, respectively.

A MERGER statement must include at least two port specifiers, and these must name an in-port and one or more unique out-ports, all of the same type. If the strings OUT= and $I N=$ are omitted, the out-port specifiers must precede the in-port specifier, which must precede any other specifiers,

In a MOVEPORT statement, the port specifiers must name two in-ports or two out-ports, both of the same type. If the strings $F R O M=$ and $T O=$ are omitted, these specifiers must occur as the first and second arguments, respectively. The first then specifies the "from" port and the second the "to" port.

The other four statements are as follows.

\begin{tabular}{|c|c|c|c|}
\hline send_statement & :. & $\operatorname{SEND}\left([\text { send control }]^{(1)}\right)$ [aroument $]$ & \\
\hline receive_statement & $\ddot{~} \ddot{:}$ & RECEIVE ([recv_control $\left.]^{(1)}\right)$ [uariable] & \\
\hline close_statement & $::$ & ENDCHANNEL ([send_control $\left.]^{(1)}\right)$ & \\
\hline probe_statement & $::$ & $\operatorname{PROBE}\left([\text { probe_control }]^{(1)}\right)$ & \\
\hline send_control & $::$ & $\begin{array}{l}\text { outport_name | PORT=outport_name } \\
\text { IOSTAT=storage_location | ERR=1abel }\end{array}$ & \\
\hline recv_control & $::$ & $\begin{array}{l}\text { inport_name | PORT=inport_name | } \\
\text { IOSTAT=storage_location | ERR=1 abel }\end{array}$ & $E N D=1$ abel \\
\hline probe_control & $::$ & $\begin{array}{l}\text { inport_name | PORT=inport_name } \\
\mathrm{ERR}=1 \text { abel } \mid\end{array}$ & EMPTY $=$ storage_location \\
\hline storage_location & $::$ & variable rlame | array_element name & \\
\hline argument & $::$ & expression 1 & \\
\hline variable & $::$ & variable_name | array_element_name & array name \\
\hline
\end{tabular}

If a port specifier does not include the optional characters PORT $=$, it must be the first item in the control information list. A storage_location specified in an IOSTAT = Or EMPTY= specifier must have integer and logical type, respectively. 


\subsection{Mapping}

The mapping annotations LOCATION and SUBMACHINE are appended to process calls:

process_call LOCATION(indices)

process_call SUBMACHINE(indices)

where indices has the same syntax as the arguments to an array_element_name.

\subsection{Restrictions}

Port variables cannot be named in EQUIVALENCE statements. Programs cannot include COMMON data; PROCESS COMMON must be used instead.

\section{Concurrency}

With two exceptions, a process executes sequentially, in the same manner as a Fortran program. That is, each statement terminates execution before the next is executed. The two exceptions are the process block and the process do-loop, in which statements execute concurrently. That is, the processes created to execute these statements may execute in any order or in parallel, subject to the constraint that any process that is not blocked (because of a RECEIVE applied to an empty channel) must eventually execute. A process block or process do-loop terminates, allowing execution to proceed to the next statement, when all its process and subroutine calls terminate.

A process can access its own process common data but not that of other processes. By default, process arguments are passed by value and copied back to the parent process, in textual and do-loop iteration order, upon termination of the process block or process doloop in which the process is called, or upon termination of the process, if the process does not occur in a process block or do-loop. A dummy argument declared INTENT(INOUT) is treated in the same way. If a dummy argument is declared INTENT(IN), then the corresponding parent argumeni is not updated upon termination. If a dummy argument is declared INTENT (OUT), the value of the variable is defined to a default value upon entry to the process.

\section{Channels}

Processes communicate and synchronize by sending and receiving values on typed communication streams called channels. A channel is created by a CHANNEL statement, which also defines the supplied in-port and out-port to be references to the new channel. A channel is a first-in/first-out message queue. An element is appended to this queue by applying the SEND statement to the out-port that references the channel. This statement is asynchronous: it returns immediately. An element is removed from the qucue by applying the RECEIVE statement to the in-port that references the channel. This statement is synchronous: it blocks until a value is available. The ENDCHANNEL statement appends an 
end-of-channel (EOC) message to the queue. The MOVEPORT statement copies a channel reference from one port variable to another.

These statements all take as arguments a control information list (cilist). The optional IOSTAT $=, E N D=$, and $E R R=$ specifiers have the same meaning as the equivalent fortran $1 /()$ specifiers, with end-of-channel treated as end-of-file, and an operation on an undefined port treated as erroneous. An implementation should also provide, as a debugging aid, the option of signaling an error if a SEND, ENDCHANNEL, or RECEIVE statement is applied to a port that is the only reference to a channel.

: $\operatorname{SEND}$ (cilist) $E_{1}, \ldots, E_{n}$ Add the values $E_{1}, \ldots, E_{n}$ (the sources) to the channel referenced by the out-port named in cilist (the target). The source values must nuatch the data types specified in the port declaration, in number and type.

1 RECEIVE(cilist) $\mathrm{V}_{1}, \ldots, \mathrm{V}_{n}$ Block until the channel referenced by the in-port named in cilist (the target) is nonempty. If the next value in the channel is not $\mathrm{EOC}$, move values from the channel into the variables $\mathrm{V}_{1}, \ldots, \mathrm{V}_{n}$ (the destinations). 'The destination variables must match the data types specified in the port declaration, in number and type.

1 ENDCHANNEL (cilist) Append an EOC: message to the channel referenced by the out-port. named in cilist.

I MOVEPORT (cilist) Copy the value of the port specified "from" in cilist (the source) to the port specified "to" (the target), and set the source port to undefined.

A port is initially undcfined. An undefined port becomes defined if it is included in a CHANNEL (or MERGER: sce below) statement, if it occurs as a destination in a RECEIVE, or if it is named as the target of a MOVEPORT statement whose source is a defined port. Any other statement involving an undefined port is erroneous.

Application of the ENDCHANNEL statement to an out-port causes that port to become undefined. The corresponding in-port remains defined until the EOC message is received by a RECEIVE statement, and then becomes undefined. Both in-ports and out-ports become undefined if they are named as the source of a SEND or MOVEPORT operation.

Storage allocated for a channel is reclaimed when both (a) either the out-port has been closed, or the out-port goes out of scope or is redefined, and (b) either EOC is received on the in-port, or the in-port goes out of scope or is redefined.

\section{Nondeterminism}

T The MERGER and PROBE statements are used to specify nondeterministic computations. M MERGER is identical to CHANNEL, except that it can define multiple out-ports to be references t. to its message queue. Messages are added to the queue as they are sent on out-ports, w with the order of messages from each out-port being preserved and all messages cventually a appearing in the queue. $A n \mathrm{EOC}$ value is added to the queue only after it has been sent. o on all oul-ports. 
The PROBE statement is used to obtain status information for a channel. It can be applied only to an in-port. The IOSTAT= and ERR= specifiers in its control list are as in the Fortran INQUIRE statement. A logical variable named in an EMPTY = specifier is assigned the value true if the channel is known to be empty, and false otherwise. Knowledge about sends is presumed to take a non-zero but finite time to become known to a process probing an in-port. Hence, a PROBE of an in-port that references a nonempty channel may signal true if the channel values were only recently communicated. However, if applied repeatedly without intervening receives, PROBE will eventually signal false, and will then continue to do so.

\section{Mapping}

The PROCESSORS declaration and the LOCATION and SUBMACHINE annotations have no semantic content, but determine performance by specifying how processes are to be mapped within an $N$-dimensional array of processors $(N \geq 1)$.

The PROCESSORS declaration is analogous to a DIMENSION statement: it declares the shape and dimensions of the processor array that is to apply in the program, process, or subroutine in which it appears. As we descend a call tree, the shape of this array can change, but its size can only become smaller, not larger.

A LOCATION annotation is analogous to an array reference. It specifies the virtual processor on which the annotated process is to execute. The specified location cannot be outside the bounds of the processor array specified by the PROCESSORS declaration.

The SUBMACHINE annotation is analogous to an array reference in a subroutine call. It specifies that the annotated process is to exccute in a virtual computer with its first processor specified by the annotation, and with additional processors selected in array element order. These processors cannot be outside the bounds of the processor array specified by the PROCESSORS declaration.

\section{References}

[1] Chandy, K. M., and Foster, I., A deterministic notation for cooperating processes, Preprint M(S.P346-0193, Mathematics and Computer Science Division, Argonne National Laboratory, Argonne, Ill., 1993.

[?] Foster, I., and Chandy, K. M., lortran M: A language for modular paralld programming, Preprint MCS-P327-0992, Mathematics and Computer Science Division, Argomne National Laboratory, Argome, Ill., 1992.

[3] Foster, I., Olson, R., and 'Tuecke, S., Programming in Fortran M, T'echnical Report ANL-93/26, Argonne National Laboratory, Argonne, III., 1993.

[4] Programming Language Fortran, American National Standard X3.9-1978, American National Standards Institute, 1978. 
Distribution for ANL-93/28

Internal:

J. M. Beumer (100)

I. T. Foster (25)

F. Y. Fradin

G. W. Pieper

R. L. Stevens

C. L. Wilkinson

TIS File

External:

DOE-OSTI, for distribution per UC-405 (54)

ANL-E Library (2)

ANL-W Library

Manager, Chicago Operations Office, DOE

Mathematics and Computer Science Division Review Committee:

W. W. Bledsoe, The University of Texas, Austin

B. L. Buzbee, National Center for Atmospheric Research

J. G. Glimm, State University of New York at Stony Brook

M. T. Heath, University of Illinois, Urbana

E. F. Infante, University of Minnesota

D. O'Leary, University of Maryland

R. E. O'Malley, Rensselaer Folytechnic Institute

M. H. Schultz, Yale University

J. Cavallini, Department of Energy - Office of Scientific Computing

$K$. Mani Chandy, California Institute of Technology

F. Howes, Department of Energy - Office of Scientific Computing 


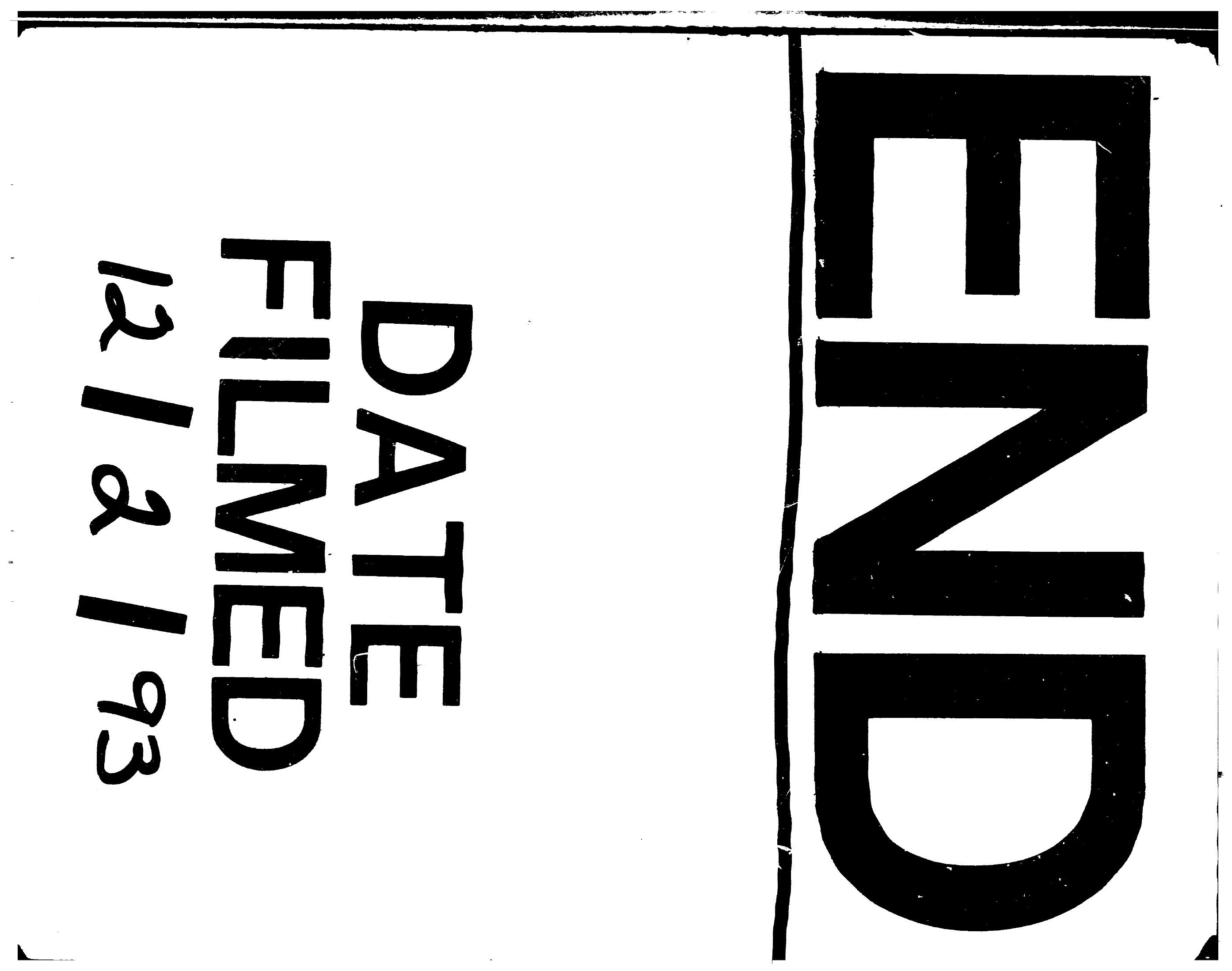


